\title{
Graphene in Aerospace Composites: Characterising Thermal Response
}

DOI:

$10.1063 / 1.5024145$

\section{Document Version}

Accepted author manuscript

Link to publication record in Manchester Research Explorer

\section{Citation for published version (APA):}

Manta, A., Gresil, M., \& Soutis, C. (2018). Graphene in Aerospace Composites: Characterising Thermal Response. In AIP Conference Proceedings https://doi.org/10.1063/1.5024145

\section{Published in:}

AIP Conference Proceedings

\section{Citing this paper}

Please note that where the full-text provided on Manchester Research Explorer is the Author Accepted Manuscript or Proof version this may differ from the final Published version. If citing, it is advised that you check and use the publisher's definitive version.

\section{General rights}

Copyright and moral rights for the publications made accessible in the Research Explorer are retained by the authors and/or other copyright owners and it is a condition of accessing publications that users recognise and abide by the legal requirements associated with these rights.

\section{Takedown policy}

If you believe that this document breaches copyright please refer to the University of Manchester's Takedown Procedures [http://man.ac.uk/04Y6Bo] or contact uml.scholarlycommunications@manchester.ac.uk providing relevant details, so we can investigate your claim.

\section{OPEN ACCESS}




\section{Graphene in aerospace composites: Characterising thermal response}

Asimina Manta, Matthieu Gresil, and Constantinos Soutis

Citation: AIP Conference Proceedings 1932, 020001 (2018); doi: 10.1063/1.5024145

View online: https://doi.org/10.1063/1.5024145

View Table of Contents: http://aip.scitation.org/toc/apc/1932/1

Published by the American Institute of Physics

\section{Articles you may be interested in}

Analytical modeling of micro and nano-composites

AIP Conference Proceedings 1932, 020003 (2018); 10.1063/1.5024147 


\title{
Graphene in Aerospace Composites: Characterising Thermal Response
}

\author{
Asimina Manta ${ }^{1, \text { a) }}$ Matthieu Gresil ${ }^{1,2, b)}$ and Constantinos Soutis ${ }^{2, c)}$ \\ ${ }^{I}$ i-composites lab, School of Materials, University of Manchester, James Lighthill Building, Sackville Street, \\ Manchester M1 3NJ, United Kingdom. \\ ${ }^{2}$ Aerospace Research Institute, Faculty of Engineering and Physical Sciences, University of Manchester, James \\ Lighthill Building, Sackville Street, Manchester M13 9PL, United Kingdom. \\ a) asimina.manta@postgrad.manchester.ac.uk \\ b) matthieu.gresil@manchester.ac.uk \\ b) Corresponding author: constantinos.soutis@manchester.ac.uk
}

\begin{abstract}
In this work, a numerical model is presented to describe the thermal response of a graphene/polymer nanocomposite. The approach is based on the multi-scale method and consists of a unit cell and a Representative Volume Element (RVE) built on a finite element interface. At the unit cell level, the material's nano-characteristics (filler geometry, phase thermal properties, interfacial properties) are employed to calculate the local thermal conductivity. The material's architecture is modelled at the RVE level by incorporating the previously obtained local thermal properties. A statistical sample was studied and the average thermal response was compared to experimental data.
\end{abstract}

\section{INTRODUCTION}

In recent years the use of lightweight composite materials in aerospace structures has steadily increased. However, the design methodology followed is still conservative, neglecting the potential benefits from the adoption of composite materials. Damage tolerance design is the most promising technique for advanced composite structures since a structure could be designed to operate in the presence of damage [1-2]. Due to the high uncertainty in predicting damage initiation, it is necessary to continuously monitor the structure's health state [3-6]. In addition to this, fibre/polymer composites suffer from performance degradation because of the environmental loading conditions. Light striking is one of the most critical events, inducing intense electrical and thermal loading. The high temperature gradients created are able to degrade rapidly the polymer's properties and damage the fibre/matrix interphase.

Aiming to facilitate the structural health monitoring and thermal management, the use of nanoparticles in the formation of nanocomposites was proposed [7-12], in order to take into advantage their effective multi-physics behaviour. These materials could be a part of a coating or even a structural part of the component. For example, they could form the matrix phase of the composite, being able to sense damage initiation and development [13-15] as well as improve the thermal and electrical conductivity of the polymer matrix [16-19].

By comparing the experimental thermal behaviour of various graphene nanocomposites, it was observed that their thermal response can be greatly affected by the manufacturing process, the material properties of the constituents, the filler's geometry and the interaction between the phases. These parameters give the designer the opportunity to form customised material structures corresponding to specific design and production requirements. However, this flexibility is time, material and financially consuming to be fully explored experimentally, and

International Conference on Structural Analysis of Advanced Materials AIP Conf. Proc. 1932, 020001-1-020001-9; https://doi.org/10.1063/1.5024145 Published by AIP Publishing. 978-0-7354-1624-6/\$30.00 
combined with the probabilistic nature of the nanocomposite, it could lead to a vast number of samples to be manufactured and tested. Therefore, a reliable numerical model should be employed first, to explore its thermal performance, taking into consideration a wide variety of aspects and provide later the background for more targeted experimentation.

The thermal response of polymer nanocomposites has been previously simulated by the Effective Medium Approach theory (EMA) and Molecular Dynamics (MD) modelling. EMA theory was used to simulate the thermal conductivity of carbon nanotube/polymer nanocomposite taking into account the effect of the carbon nanotube diameter, aspect ratio, thermal conductivity and interfacial thermal resistance [20]. Multi-scale MD simulation was used in [21] to predict the interfacial resistance of functionalised carbon nanotubes. In the same work, an analytical model to predict the resulting effect on the bulk thermal conductivity of the nanocomposite was presented. MD simulations were also adopted to estimate the interfacial thermal resistance between parallel single-wall carbon nanotubes as a function of nanotube spacing, overlap and length [22]. Theoretically calculated and experimentally measured thermal conductivity of epoxy in the liquid (nanofluid) and solid (nanocomposite) states were compared, using both rod-like and platelet-like carbon-based nanostructures [23].

Similarly, a theoretical model [24] and combined molecular dynamics - finite element multiscale models [25-27] were proposed for the prediction of thermal conduction of graphene/polymer nanocomposites. More specifically, an analytical model based on the framework of differential-effective-medium (DEM) theory was produced and compared to EMA approximation and available experimental results [24]. In combined multi-scale schemes, molecular dynamics are used for the investigation of thermal conduction in graphene/epoxy assembly at atomic scale to calculate the thermal boundary conductance between crosslinked epoxy and graphene sheet, while a FEbased representative volume element (RVE) of the nanocomposite was employed to evaluate the thermal conductivity at the microscale structure [25-27].

The theoretical/analytical models, in general, do not take into consideration the nanocomposite architecture, while the interaction between the nanoparticles is not properly analysed as it is assumed that their relative distance is greater than the thickness of the interface between the polymer and the graphene. Although the multi-scale combined MD-FE models are found to be an accurate representation of the thermal conduction taking place between the fillers' interface and the bulk nanocomposite material, the use of MD simulations for the calculation of the boundary resistance between the filler and the matrix is extremely complicated. Furthermore, none of the aforementioned theories has presented any prediction on the thermal transient response of the graphene/polymer nanocomposite.

In this numerical study, following the work presented in [28], a FE multi-scale model is proposed, consisting of a unit cell that predicts the local thermal response and a representative volume element (RVE), which calculates the overall thermal performance of the nanocomposite taking into account its detailed architecture. Numerical results are compared with analytical and experimental data found in literature and measured by our research group. Particularly, the model was used to simulate the steady behaviour of graphene/PA-6 [24] and GnP/epoxy systems [29].

\section{MODEL OVERVIEW}

\section{Unit Cell}

In the unit cell analysis, the main purpose is to simulate the local thermal transport phenomena taking place between the filler and the matrix (resin). The unit cell consists of the filler, the interfacial volume between the matrix and the filler, and the matrix, while it is shaped as the filler. The ratio of the different phase volumes is related to the volume fraction $V_{\mathrm{f}}$ of the nanocomposite studied. In the current study, the unit cell is assumed circular with diameter $\mathrm{W}$ and thickness $\mathrm{T}$. The ratio of $\mathrm{W}$ to $\mathrm{T}$ is assumed to be the same as the ratio of the filler's diameter $\mathrm{d}$ to the filler's thickness $t(1)$, while the $\mathrm{W}$ is connected to $\mathrm{d}$ through equation (2). The interfacial volume between the filler and the matrix is modelled as a constant volume with in-plane thickness $c_{x y}$ and through-the-thickness thickness $c_{z}$. The geometrical characteristics and dimensions are presented in Fig. 1. 


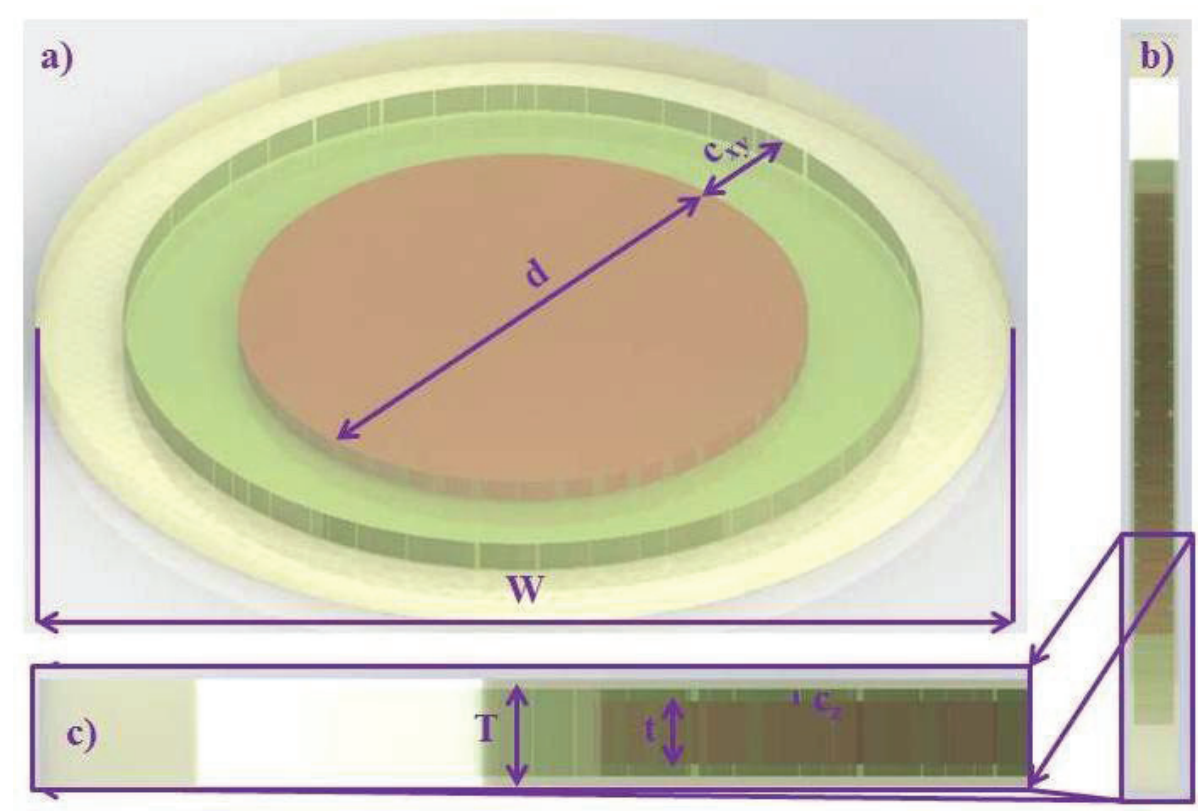

FIGURE 1. Unit cell 3D solid model a) Isometric view, b) Side view, c) Detail of side view

In terms of material properties, it has been assumed that the thermal response of all phases is temperature independent and constant to the properties measured at room temperature, while the matrix is expected to behave isotropically compared to the other two phase behaving transversely isotropically. These properties are presented in Table 1 and 2. The interfacial thermal interaction between graphene and matrix is approached by the Kapitza resistance [30]. This thermal resistance is considered to be constant for a specified distance equal to the mean free path of the polymer and it represents the resistance created because of the phonon interaction in the phases boundary, macroscopically defined as the (3), where is the heat flux in the boundary area, $\Delta \mathrm{T}$ is the temperature drop and $R_{k}$ is the Kapitza resistance. In terms of physics, $R_{k}$ is the result of the weak phonon-phonon coupling leading to a backscattering of phonos at the interface, which acts as a barrier of the heat flow and thus decrease the overall thermal conductivity. Theoretically, the Kapitza resistance could be calculated by two theories - the acoustic mismatch model (AMM) and the diffuse mismatch model (DMM) [31]. In AMM, for an interface between dissimilar materials, the different densities and sound speeds result in a mismatch in the acoustic impedances; this is directly analogous to the mismatch in the refractive indices of two optically different materials. By assuming that no scattering takes place at the interface, and by imposing appropriate stress and displacement boundary conditions [32] at the interface, the AM model gives the transmission coefficient $t_{\mathrm{AB}}$ for phonon energy in material $\mathrm{A}$ incident normal to the interface with material B as (4) [33], where $\mathrm{Z}=\rho \mathrm{c}$ is the acoustic impedance with $\mathrm{c}$ and $\rho$ being the speed of sound and mass density respectively. Considering that both sides of the interface are identical, the resistance could be computed by the (5) [33], where $\mathrm{k}_{\mathrm{B}}$ is the Boltzmann constant, is the Plank constant devided by $2 \pi, \mathrm{c}$ is the speed of sound and T is absolute temperature. By contrast, in the DM model theory it is assumed that all phonons striking an interface lose the memory of where they came from. Then, the probability of being scattered to one side of the interface or the other is simply proportional to the phonon density of states. Thus, as in the AM model, the fraction of energy transmitted is independent of the interface structure. In the low-temperature limit, the thermal boundary resistance in the limit of diffuse mismatch can be written as (6) [33].

$$
\begin{gathered}
\frac{W}{T}=\frac{d}{t} \\
V_{f}=\frac{V_{\text {filler }}}{V_{\text {UnitCell }}} \Rightarrow W=d^{1 / 3} \sqrt{\frac{1}{V_{f}}} \\
\dot{Q}=\frac{\Delta T}{R_{k}}
\end{gathered}
$$




$$
\begin{gathered}
t_{A B}=\frac{4 Z_{A} Z_{B}}{\left(Z_{A}+Z_{B}\right)^{2}} \\
R_{k}=\left[\frac{\left.\pi^{2} k_{B}^{4}\left(\sum_{j} c_{1, j}^{-2}\right)\right]^{-1} \cdot T^{-3}}{30 \hbar^{3}}\right. \\
R_{k}=\left[\frac{\pi^{2} k_{B}^{4}}{30 \hbar^{3}}\left(\frac{\sum_{j} c_{1, j}^{-2} \sum_{j} c_{3-i, j}^{-2}}{\sum_{i, j} c_{i, j}^{-2}}\right)\right]^{-1} \cdot T^{-3}
\end{gathered}
$$

For the purposes of this simulation work, the AMM theory has been used for the estimation of the Kapitza Resistance. The methodology followed is summarised as:

1. Determining the elastic properties, density of the phases and the temperature.

2. Calculation of longitudinal and transverse wave velocities for both phases in accordance with the theory of the analytical calculation bulk wave modes [34] for incident angle lying in filler's plane.

3. Calculation of reflection and transmission angles for any in-plane incident wave angle with the application of the relation of the Sneil-Descartes.

4. Calculation of energy transmission coefficient for each mode [32].

5. Calculation of $\Gamma$ coefficient for each mode (7), as well as the total $\Gamma$ coefficient (8).

$$
\begin{gathered}
\Gamma_{i}=\int_{0}^{\pi / 2} \alpha_{i}\left(\theta_{o}\right) \sin \theta_{o} \cos \theta_{o} d \theta_{o}, i=1 l, 1 t, 1 t 2 \\
\Gamma_{t o t}=\Gamma_{1 l}+\eta_{1}^{2}\left(\Gamma_{1 t 1}+\Gamma_{1 t 2}\right)
\end{gathered}
$$

6. Calculation of Kapitza Resistance

Finally, the Kapitza resistance is calculated by (9), where $\mathrm{k}_{\mathrm{B}}$ is the Boltzmann constant and $\hbar$ is the Plank constant divided by $2 \pi$. The Kapitza resistance for each nanocomposite case was calculated as in:

$$
R_{k}=\left[\frac{\pi^{2} k_{B}^{4}}{15 \hbar^{3}} c_{1 l}^{-2} \Gamma_{t o t}\right]^{-1} \cdot T^{-3}
$$

The structure proposed was modelled in the commercial software ANSYS 16.2. The finite element used is the Solid278, which is a homogeneous 3D 8-node thermal solid element. The model is presented in Fig. 2. The in-plane thermal conductivity (xy-conductivity $\mathrm{K}_{\mathrm{xy}}$ ) is calculated by fixing the temperature in the unit cell perimeter and at a circle close to the centre, while the through-the-thickness thermal conductivity (z-conductivity $\mathrm{K}_{\mathrm{z}}$ ) is calculated by fixing the temperature on the top and bottom faces. 


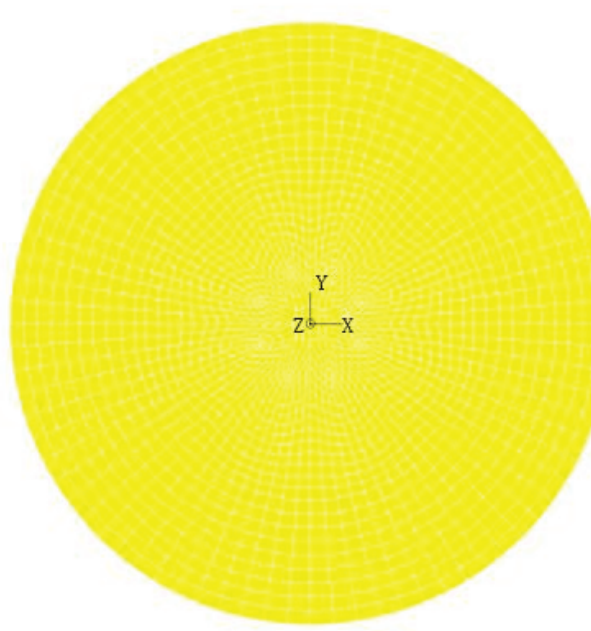

Unit Cell Top View

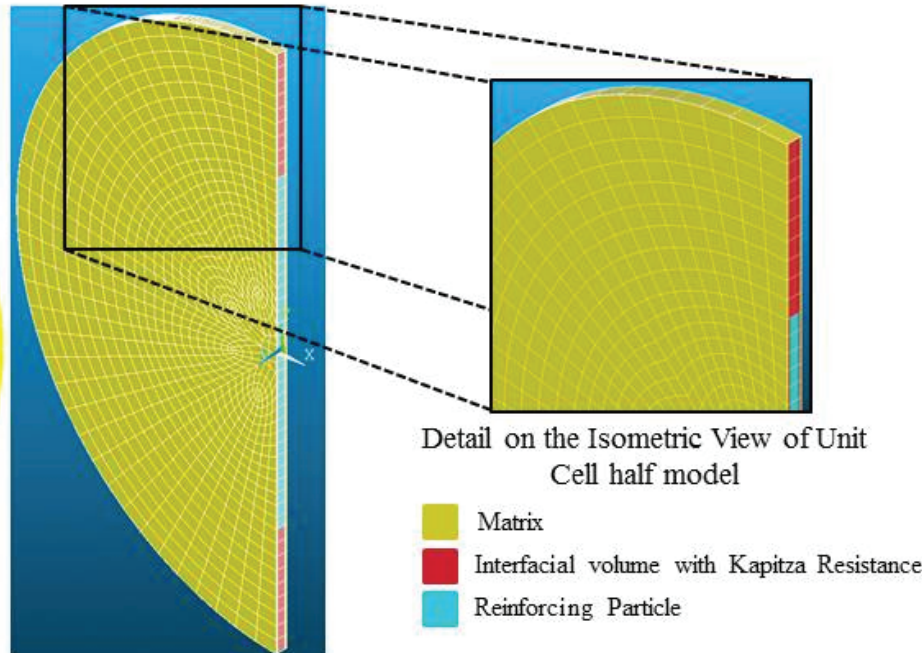

Isometric View of Unit Cell half model

FIGURE 2. Unit cell finite element model

At first, two graphene/polymer nanocomposite structures were studied. The first one is the Graphene/PA-6 composite studied by K. Chu et al. [24] and the second one is GnP/epoxy composite manufactured by our research group [29]. The material properties assumed in each case are summarised in Table 1 and 2. The graphene particles embedded in the PA- 6 have a diameter of $2 \mu \mathrm{m}$ and thickness of $1.7 \mathrm{~nm}$, while the $\mathrm{GnP}$ reinforcing epoxy has a diameter of $25 \mu \mathrm{m}$ and thickness of $6 \mathrm{~nm}$.

TABLE 1. Thermal material properties nanocomposites' phases.

\begin{tabular}{|c|c|c|c|c|c|c|c|}
\hline \multirow[t]{2}{*}{ Nanocomposite } & \multirow[t]{2}{*}{ Phase } & \multirow[t]{2}{*}{$\begin{array}{c}\text { Density } \\
\rho_{\mathrm{i}}\left(\mathrm{kg} / \mathrm{m}^{3}\right)\end{array}$} & \multirow[t]{2}{*}{$\begin{array}{c}\text { Specific } \\
\text { Heat } \\
\text { Capacity } \\
C_{i}(\mathbf{J} / \mathbf{k g K}) \\
\end{array}$} & \multicolumn{2}{|c|}{$\begin{array}{c}\text { Thermal } \\
\text { Conductivity } K_{i}^{j} \\
(\mathbf{W} / \mathbf{m K})\end{array}$} & \multicolumn{2}{|c|}{$\begin{array}{l}\text { Thermal Diffusivity } \\
\qquad \alpha_{i}^{j}\left(\mathbf{m}^{2} / \mathbf{s}\right)\end{array}$} \\
\hline & & & & $\begin{array}{l}\text { In- } \\
\text { plane } \\
(j=x y)\end{array}$ & $\begin{array}{l}\text { Through- } \\
\text { the- } \\
\text { thickness } \\
\quad(j=z)\end{array}$ & $\begin{array}{c}\text { In-plane } \\
(j=x y)\end{array}$ & $\begin{array}{c}\text { Through- } \\
\text { the- } \\
\text { thickness } \\
\quad(j=z)\end{array}$ \\
\hline \multirow[t]{2}{*}{$\begin{array}{c}\text { Graphene/PA-6 } \\
{[24]}\end{array}$} & $\begin{array}{l}\text { Graphene } \\
\quad(i=f)\end{array}$ & 2000 & 1538 & 2000 & 6 & $6.510^{-4}$ & $1.9510^{-6}$ \\
\hline & PA-6 $(i=m)$ & 1140 & 1700 & \multicolumn{2}{|c|}{0.2} & \multicolumn{2}{|c|}{$1.03210^{-7}$} \\
\hline \multirow{2}{*}{$\begin{array}{c}\text { Graphene/Epoxy } \\
{[29]}\end{array}$} & $\begin{array}{c}\text { Graphene } \\
\quad(i=f)\end{array}$ & 1130 & 2722 & 2000 & 6 & $6.510^{-4}$ & $1.1010^{-6}$ \\
\hline & Epoxy $(i=m)$ & 1130 & 1070 & \multicolumn{2}{|c|}{0.18} & \multicolumn{2}{|c|}{$1.48910^{-7}$} \\
\hline
\end{tabular}

TABLE 2. Kapitza Resistance calculated for each nanocomposite.

\begin{tabular}{ccccc}
\hline Nanocomposite & $\begin{array}{c}\text { In-plane } \\
\text { Kapitza } \\
\text { Resistance } \\
\left(\mathbf{m}^{2} \mathbf{K} / \mathbf{W}\right)\end{array}$ & $\begin{array}{c}\text { Through the } \\
\text { thickness Kapitza } \\
\text { Resistance } \\
\left(\mathbf{m}^{2} \mathbf{K} / \mathbf{W}\right)\end{array}$ & $\begin{array}{c}\text { In-plane Kapitza } \\
\text { Resistance } \\
\text { thickness }(\mathbf{n m})\end{array}$ & $\begin{array}{c}\text { Through the } \\
\text { thickness Kapitza } \\
\text { Resistance } \\
\text { thickness }(\mathbf{n m})\end{array}$ \\
\hline $\begin{array}{c}\text { Graphene/PA-6 [24] } \\
\text { Graphene/Epoxy [29] }\end{array}$ & $8.410^{-8}$ & 420 & $0.025210^{-8}$ & 2 \\
\hline
\end{tabular}




\section{Representative Volume Element (RVE)}

The RVE is a rectangular block, on which thermal properties previously obtained through the unit cell are distributed according to a user defined distribution. The block's side is equal to multiplied maximum nanoparticle's dimension $\mathrm{d}(\mathrm{k} \cdot \mathrm{d})$. As it has been proven in [35] for the case of the electrical performance modelling, for $\mathrm{k}=5$ the sample's characteristics have converged and they are representative of the nanocomposite's architecture. The unit cell's material properties' distribution represents the position of graphene on the bulk volume of polymer nanocomposites, while it is related to the nanocomposite's manufacturing process. Finally, the orientation of graphene is simulated by the $3 \mathrm{D}$ random orientation of the corresponding element local coordinate system, while the range of the angles is subject to be reviewed in relation to the nanocomposite's manufacturing process and/or if any particle alignment mechanism takes place (application of electric or magnetic field, for example).

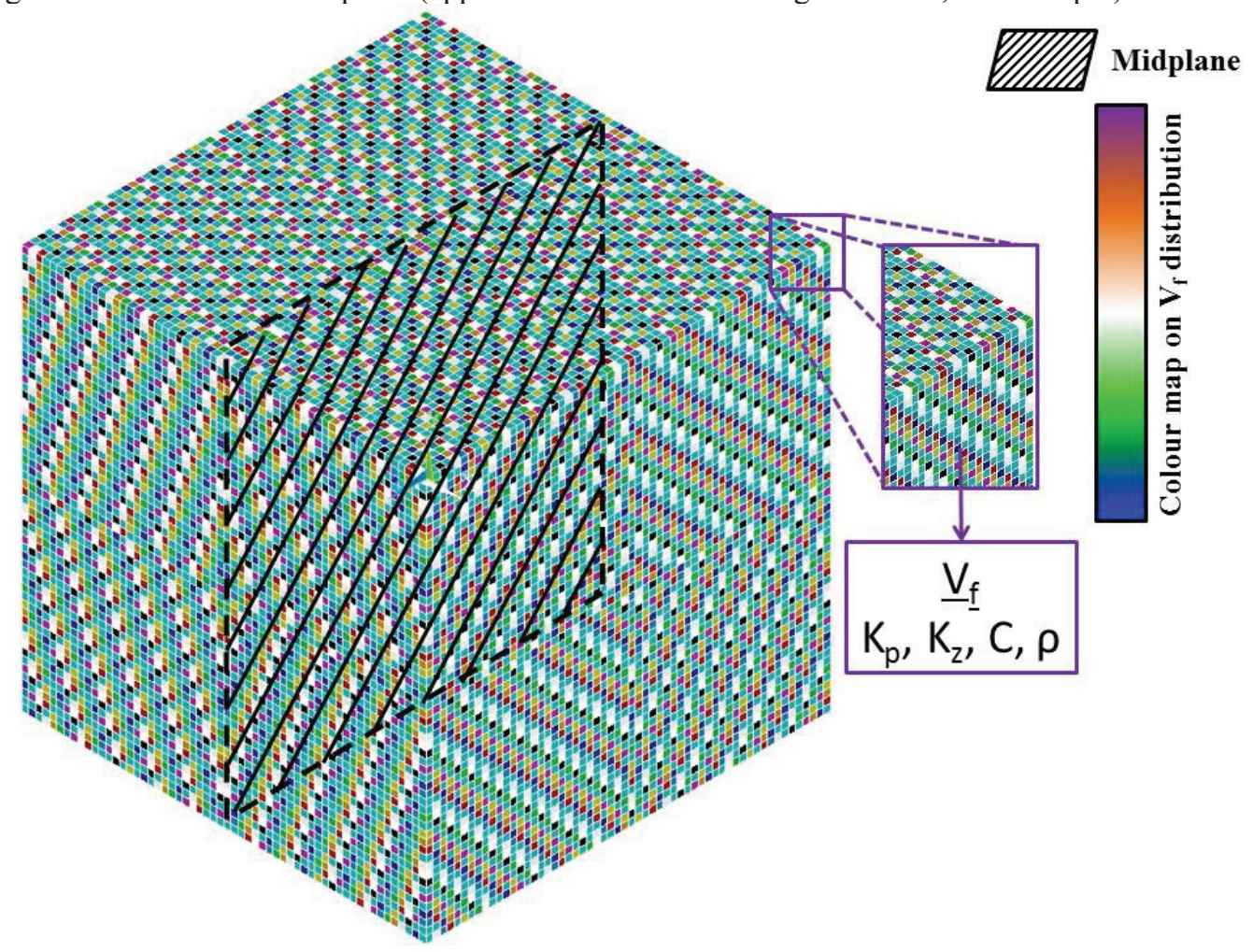

FIGURE 3. RVE and symmetric distribution of the thermal properties of the unit cell. Every element is characterised by a $V_{f}$ and its corresponding properties

The RVE is meshed with a number of elements (nn) equal to the number of graphene particles having the same volume with the RVE's volume (10). Finally, each side is discretised by eis divisions (11). The distribution of the material properties is requested to be symmetric about the midplane, as it is requested by the assumptions for the analytical solution of 1D transient conduction problem. The details of the RVE, the plane symmetry and an indicative $\mathrm{V}_{\mathrm{f}}$ distribution are depicted in Fig. 3.

$$
\begin{aligned}
& n n=\operatorname{round}\left(\frac{4 k^{3} d}{\pi t}\right) \\
& \text { eis }=\text { round }(\sqrt[3]{n n})
\end{aligned}
$$

Thermal conductivity is calculated by the Fourier law (12), where $\mathrm{k}$ is the thermal conductivity, A is the area, $\mathrm{T}$ is temperature and $r$ is the distance.

$$
\dot{Q}=-k A \frac{\partial T}{\partial r}
$$




\section{RESULTS}

The numerical results are compared with experimental and theoretical ones. The experimental data are those found in literature [24] and produced by our Research Group [29], while the theoretical results followed a model based on the Differential-Effective-Medium (DEM) theory (Fig. 4). The average thermal conductivity is the output of the analysis of a statistical sample of fifty (50) specimens with Gaussian distribution of volume fraction with standard deviation $\sigma=\mu / 8$. It should be noted that the proposed model is capable to simulate well the theoretical thermal response of graphene/polymer nanocomposites. Thermal conductivity is an increasing nonlinear function of volume fraction while low volume fraction nanocomposites exhibit linear trend. Nonlinearity is the result of ratio of interfacial thickness to interparticle distance. When the interfacial thickness is comparable to the inter-particle distance, the boundary regions formed around reinforcing particles tend to overlap, leading to a nonlinear system of local thermal resistances and temperature drop.

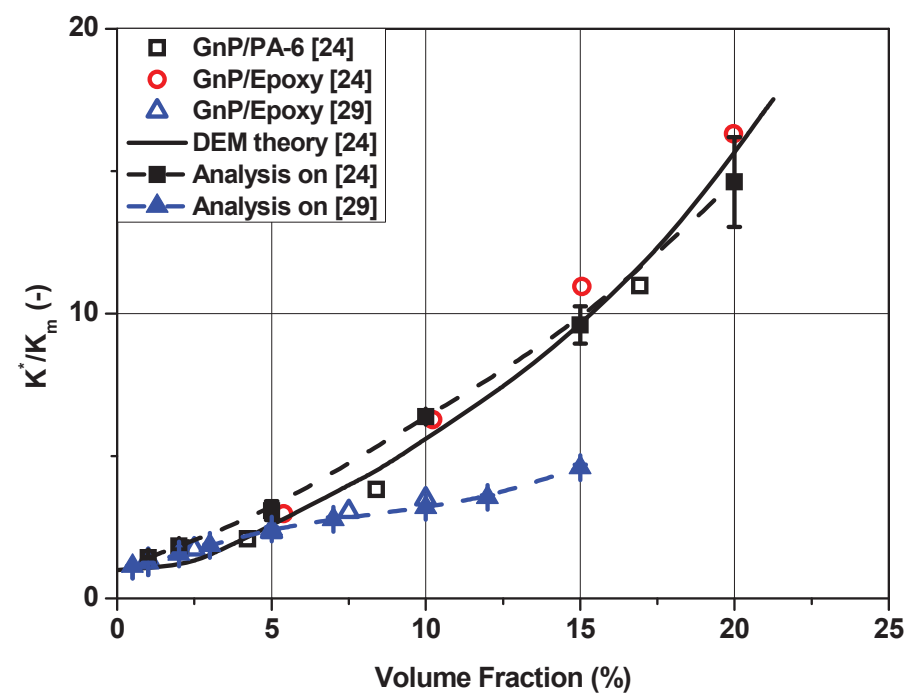

FIGURE 4. Comparison of the FE model with experimental results and DEM model in terms of thermal conductivity

The effect of assuming different local $\mathrm{V}_{\mathrm{f}}$ distributions on the statistical nature of the thermal conductivity for the case of GnP/epoxy nanocomposite [29] is presented in Fig. 5. For low $\mathrm{V}_{\mathrm{f}} \mathrm{S}(<7 \%)$, the effect of the material distribution is negligible. For increasing $\mathrm{V}_{\mathrm{f}}(>7 \%)$, the type of distribution affects more evidently the average thermal conductivity, while the exponential distribution produced highest errors. For $\mathrm{V}_{\mathrm{f}}=15 \%$, uniform distribution exhibited the highest average thermal conductivity, while the Gaussian distribution with standard deviation $\sigma=\mu / 16$ resulted in the lowest average thermal conductivity. It could be seen that $\mathrm{V}_{\mathrm{f}}=7 \%$ is a threshold value for the transition from the linear to the nonlinear region as well as for the important impact of local volume fraction distribution in the bulk material. Therefore, the nonlinear behaviour could be linked to the filler's distribution and its characteristics. 


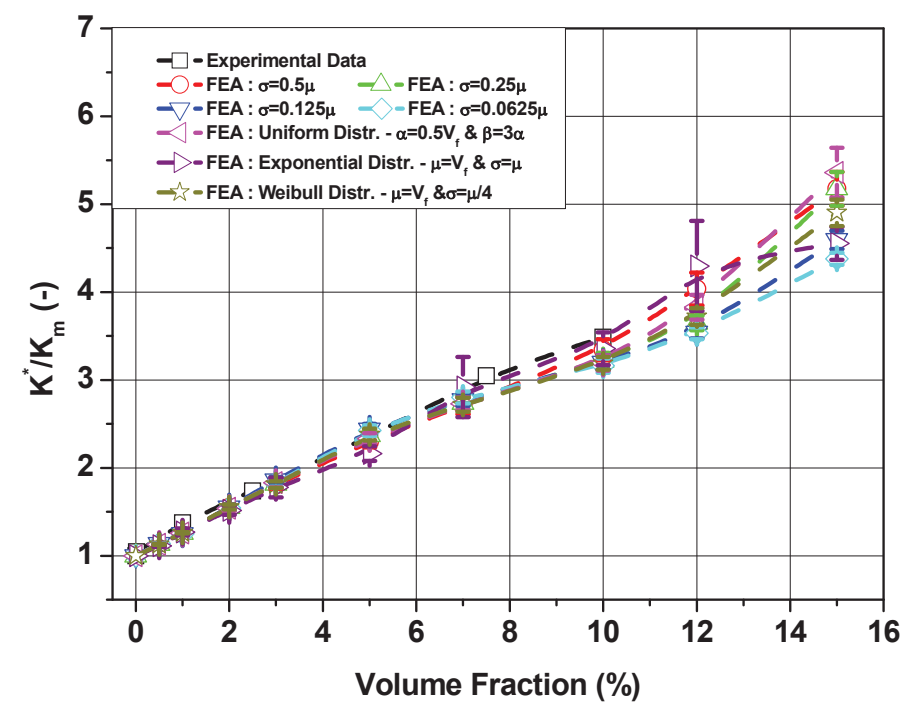

FIGURE 5. Effect of local $\mathrm{V}_{\mathrm{f}}$ distribution on the thermal conductivity of graphene/polymer nanocomposites

\section{CONCLUSIONS}

The thermal response of two different nanocomposite systems - graphene/PA-6 and GnP/epoxy - was simulated and compared to a DEM theory. The model was found to simulate well the nanocomposite thermal behaviour. The effect of filler distribution on thermal conductivity was examined, indicating that for low $V_{f}$ distribution, it has a minor effect when compared to higher $\mathrm{V}_{\mathrm{f}} \mathrm{s}$, where the type of distribution affects more evidently the average thermal conductivity, with the exponential one producing highest errors. For volume fractions in which the interparticle distance is comparable to the interfacial thickness, nonlinear effect occurs in heat transport, leading to a greater sensitivity of the thermal response on the filler distribution and production of significant standard deviation of the statistical sample. The most important challenge in simulating the thermal response is the determination of the thermal properties of graphene, which exhibits high deviation and dependence on graphene nano-structure and manufacturing process.

\section{REFERENCES}

1. C. Soutis, Mater. Sci. Eng. A, 412, 171-176 (2005).

2. R. Talreja and C. V. Singh, Damage and failure of composite materials (Cambridge University Press, 2012).

3. S. Pavlopoulou, W. J. Staszewski, and C. Soutis, Struct. Control Heal. Monit., 20, 937-955 (2013).

4. S. Pavlopoulou, K. Worden, and C. Soutis, J. Intell. Mater. Syst. Struct., 27, 549-566 ( 2016).

5. Z. Li, A. Haigh, C. Soutis, A. Gibson, R. Sloan, and N. Karimian, Compos. Struct., 140, 252-261 (2016).

6. B. Yu, R. Blanc, C. Soutis, and P. J. Withers, Compos. Part A Appl. Sci. Manuf., 82, 279-290 (2016).

7. E. K. Sichel, J. I. Gittleman, and P. Sheng, J. Electron. Mater., 11, 699-747 (1982).

8. Y. Ishigure et al., J. Mater. Sci., 34, 2979-2985 (1999).

9. G. Pinto and A. Jiménez-Martín, Polym. Compos., 22, 65-70 (2001).

10. V. I. Roldughin and V. V Vysotskii, Prog. Org. Coatings, 39, 81-100 (2000).

11. L. Flandin, J. Y. Cavaillé, G. Bidan, and Y. Brechet, Polym. Compos., 21, 165-174 (2000).

12. A. Quivy, R. Deltour, A. G. M. Jansen, and P. Wyder, Phys. Rev. B, 39, 1026-1030 (1989).

13. V. Kostopoulos, A. Vavouliotis, P. Karapappas, P. Tsotra, and A. Paipetis, J. Intell. Mater. Syst. Struct., 10, 1025-1034 (2009).

14. M. Nofar and S. Hoa, Compos. Sci. Technol., 69, 1599-1606 (2009).

15. L. M. Chiacchiarelli, M. Rallini, M. Monti, D. Puglia, J. M. Kenny, and L. Torre, Compos. Sci. Technol., 80, 73-79 (2013). 
16. Y. Song et al., JMADE, 88, 950-957 (2015).

17. C. Yun, Y. Feng, T. Qiu, J. Yang, X. Li, and L. Yu, Ceram. Int., 41, 8643-8649 (2015).

18. E. Kandare et al., Compos. PART A, 69, 72-82 (2015).

19. J. Renteria et al., JMADE, 88, 214-221 (2015).

20. C.-W. Nan, G. Liu, Y. Lin, and M. Li, Appl. Phys. Lett., 85, 3549 (2004).

21. T. C. Clancy and T. S. Gates, Polymer, 47, 5990-5996 (2006).

22. H. Zhong and J. R. Lukes, Phys. Rev. B, 74, 125403 (2006).

23. M. Martin-Gallego, R. Verdejo, M. Khayet, J. M. Ortiz de Zarate, Essalhi Mohamed, and M. A. LopezManchado, Nanoscale Res. Lett., 6, 610 (2011).

24. K. Chu, W.-S. Li, H.-F. Dong, and F.-L. Tang, EPL, 100, 36001 (2012).

25. B. Mortazavi, O. Benzerara, H. Meyer, J. Bardon, and S. Ahzi, Carbon, 60, 356-365 (2013).

26. B. Mortazavi et al., Thermochim. Acta, 552, 106-113 (2013).

27. B. Mortazavi and T. Rabczuk, Carbon, 85, 1-7 (2015).

28. A. Manta, M. Gresil, and C. Soutis, Appl. Compos. Mater., 24, 281-300 (2017).

29. M. Gresil, Z. Wang, Q.-A. Poutrel, and C. Soutis, Sci. Rep.,7,5536 (2017).

30. G. L. Pollack, Rev. Mod. Phys., 41, 48-81 (1969).

31. D. G. Cahill et al., J. Appl. Phys., 93, 793 (2003).

32. J. D. N. Cheeke, B. Hebral, and C. Martinon, La Journal de Physique, 34, 257-272 (1973)

33. E. T. Swartz and R. O. Pohl, Rev. Mod. Phys., 61, 605-668 (1989).

34. A. H. Nayfeh, Wave propagation in layered anisotropic media with applications to composites. (Elsevier, 1995).

35. A. Manta, M. Gresil, and C. Soutis, "Multi-Scale Finite Element Analysis of Graphene/Polymer Nanocomposites: Electrical Perfomance," in VII European Congress on Computational Methods in Applied Sciences and Engineering (2016). 